\title{
The capability of pulsed laser radiation for cutting band saws hardening
}

\author{
Evgeny Marinin ${ }^{1, *}$, Denis Sergeev ${ }^{1}$, and Nadezhda Marinina ${ }^{2}$ \\ ${ }^{1}$ FSBEI HE «VyatSU», FTED, 36, Moskovskaya street, Kirov city, Kirov region, 610000, Russian Federation \\ ${ }^{2}$ FSBEI HE «VyatSU», FL, 36, Moskovskaya street, Kirov city, Kirov region, 610000, Russian Federation
}

\begin{abstract}
The article deals with the possibilities of pulsed laser radiation for hardening the band saws. The regimes of pulsed laser hardening the band saws of $1 \mathrm{~mm}$ thick made of tool steel $9 \mathrm{CrV}$ are grounded theoretically and experimentally tested. Selected and justified modes of treatment harden in the autohardening mode without additional heat removal. The results of the experimental research of microhardness are presented and formed as a result of processing of the microstructure. Selected modes increase the microhardness of the surface to $8500 \mathrm{MPa}$ and form ultra highly dispersed structure in the surface layer characterized by high resistance to abrasion.
\end{abstract}

\section{Work actuality}

Band saw machines are widely used at sawing wood species. Also band saw machines for metal and contour band saw technology for metal cutting are more and more used due to its advantages: high productivity; high quality and accuracy of cutting; tool durability; low energy consumption; convenience and simplicity of service.

The band saw machines operate with the fine band saw max. 1-1,5 mm. thick To achieve optimum conditions when working with certain groups of materials and blanks form it is necessary to define exactly the parameters of the saw blade: the tooth spacing, the shape and the saw wrest, the tensile force and the operation modes of band saw machine.

Saws welded in a ring (loop) of a certain length are used in band saw machines. Welding of saws in the loops is performed by melting with the specialized welding units of butt-steam contact welding. It is a thermomechanical process of formation of metal permanent connections, when local heating of the welded parts entails plastic deformation, developing under the influece of the compressive force.

The band saws from carbon steels and bimetal - with spring base and teeth of high speed steel or hard alloy are used for modern band saw technologies of metals processing. The variety of constructive options of band saws and the use of optimal modes of cutting provide high productivity and reduce the cost of technological processing at the band saw machines compared to other methods of spacer cutting blanks.

Band saws made of qualitative high carbon tool steel is designed for economical cutting of various alloyed and non-alloyed steels; but according to its technical and operational indicators they are inferior to the bimetal blades.

Bimetal blades with the tooth of high speed steel are the most widely used in modern sawing technology. This steel has high hardness and red hardness. Specially selected spring steel of the saw foundations gives it strength and durability. The reliable electron-beam welded joint with the cutting teeth allows to use these saws in the most difficult production conditions.

The short-term operation of each tooth during the cutting, the normal cooling and lubrication determine the relatively long-term service of the saw.

Each instrument has a certain performance and durability relation. The durability of the saw tooth and the durability of the blade to the cyclic alternating loads appear from the movement of the saw in the tape mechanism of the band saw.

To extent the service life of the saw it is necessary to run a saw with a gradual increase of the tooth load. It should also be noted that the running of a band saw is always performed with the light processing materials, regardless of what material is used after the grinding of the the band saw.

To achieve the optimal conditions when working with certain material groups and the shape of the blanks it is necessary to select the parameters of the saw blade accurately: the pitch, the shape, the saw tooth setting and the operating modes of the band saw machine - the speed and the feed of the band saw.

There is a problem of choice of band saw blade parameters in the process of production equipment with the band saws to ensure the most appropriate results [1]. Analyzing the available information we conclude that the resistance of band saws depends mostly on the combination of the following factors [2]:

\footnotetext{
Corresponding author: e.marrini@gmail.com
} 
1. The accuracy of selection of settings for cutting modes: cutting speed $(\mathrm{m} / \mathrm{min})$ and productivity $\left(\mathrm{cm}^{2} / \mathrm{min}\right)$.

2. The correct selection of the blade parameters (type and size, material, brand, shape of the tooth form, tooth spacing) depends on the shape and material of the cut blanks.

3. The material grade and the shape of processed blanks and the quality of the blanks material.

4. The design features of the band saw equipment.

5. Technical state of the band saw equipment and its independent units (unit of tension, pulleys and bearings, carbide and roller guides, the uniformity and the smooth lowering of the sawing frame).

6 . The quality and concentration of the used cutting coolant.

7. The quality of the run-in new band blade.

The main reasons for premature failure of the band saws [2]:

1. Punching out (knocking out) of the teeth. This is due to the following reasons: the saw's pitch is too small or the saw's pitch is too large; the blanks are not securely attached; the saw's speed is too slow resulting in excessive plunging; too high supply pressure resulting in excessive sawing into the material; weak tension of the saw leads to slippage; slipping (stopping) of the saw under the load, resulting in excessive cutting of the saw into the material, the cleaning brush of the saws does not work or is worn out.

2. The cracks of the teeth grooves. It is caused by: the difficult movement of the saw in the guides and pulleys due to the contamination of the pulleys or the reduction of the gap in the guides; the gap between the guides is too large; the guides are too far from the blank; the side guides clamp the saw in the tooth grooves area; the slightly clamped side guides lead to the tilt of the saw; the wrong tension of the saw.

3. The cracks of the back of the saw. The reasons of it may: wear of the upper support bearing in the guides, high supply pressure, wear of the side guides, the blade is pressed against the pulley shoulder.

4. Beating (vibration) of the saw. It can be caused by: the curved weld seam, the wrong pitch of the saw, the absence of teeth (broken), too low or high delivery pressure.

5. The premature blunting of the teeth. It can be caused by: too high saw speed for this material, too small or too large pitch of the saw, saw blade are not parallel to the feed direction, defects at the side guides, poorly fixed or worn guides.

The performance and durability [3] are the criteria of tools quality. They are determined by the material properties of blade and methods of processing and hardening.

There are many methods of hardening to increase durability of the cutting tools: rigging tool teeth with the carbide plates; electrocontact hardening and tempering of the teeth in the high-frequency current field; the use of thermochemical or thermomechanical treatment technologies, the method of electric spark machining and others [4].
There is a method of hardening the narrow band saws [5] by the elastic-plastic deformation of a saw blade creating a pre-curved condition and compressive stress on the saw surface. It leads to decrease of amplitude values of stresses in the saw during the operation [6].

Thus, the problem of hardening the cutting band saws is undoubtedly the task of today.

The aim of this work is to determine the possibility of hardening the saw blades with the laser hardening by pulsed solid state laser, analytical selection of hardening modes and their experimental approbation.

\section{Theoretical part}

Rather promising method of hardening the material of band saws is laser hardening. This kind of hardening treatment is studied properly but is not widespread nowadays. Laser hardening hardens both structural and tool steels [7-9]. The ultra-fine structure characterized by high strength and plasticity is formed as the result of properly chosen modes of such hardening treatment on the surface of impact $[9,10]$. This combination of mechanical characteristics is required for band saws. Also the laser treatment allows to create compressive stress in the surface layer [9], that affects positively the wear resistance of band saws [5].

The choice of laser hardening modes of the band saw at the last stage of preparation for work is an interesting challenge at the turn of science and industry. The following requirements is fulfilled when performing the laser hardening:

1. preserving the original surface roughness;

2. ensuring the maximum depth of the hardened zone;

3. reducing the heat affected area having reduced mechanical strength;

4. the possibility of technological reproducibility of the process.

These requirements mean that the laser hardening is made without melting the surface with a minimal energy expenditure into hardened saw and the cooling is made by the heat removal into the material. The option of heat removal from the product during laser treatment limits the technological reproducibility of the process and increases the cost of treatment and reduces productivity.

The installations generating pulsed laser radiation provide a minimal energy expenditure in the surface layer and technological reproducibility. Such equipment reduces significantly the heat input to the workpiece by the pulse energy selection, its time and pulses frequency.

\section{The methodology of the experiment}

The samples of band saws of $1 \mathrm{~mm}$. thick were subjected to the laser hardening. The samples material is tool steel $9 \mathrm{CrV}$ subjected to bulk oil hardening from $850 \mathrm{C}$ and tempering at $250 \mathrm{C}$. This type of pre-heat treatment get higher values of mechanical characteristics by laser hardening [11]. The installation HTF-100 is used as the source of laser radiation. 
The time of the laser pulse is found at the heat affected area $200 \mu \mathrm{m}$ max. and technological equipment capability:

$$
h_{t}=2 \cdot \sqrt{a \cdot \tau_{i}}
$$

where $h_{t}$ - depth of heat penetration during the laser pulse, $\mathrm{m} ; \tau_{i}$ - time of laser pulse, sec; $a$ - heat diffusivity of material, $\mathrm{m}^{2} / \mathrm{s}$ determined by the formula:

$$
a=\frac{\lambda}{\rho c}
$$

$\lambda$ - heat diffusivity of steel $9 \mathrm{CrV}, \lambda=52,3 \mathrm{~W} / \mathrm{m} \mathrm{K}$ [12], $\rho$ - steel $9 \mathrm{CrV}$ density, $\rho=7790 \mathrm{~kg} / \mathrm{m}^{3}$ [12], $c-$ heat capacity of steel $9 \mathrm{CrV}, c=486 \mathrm{~J} / \mathrm{kg} \cdot \mathrm{K}[12]$.

For experimental work the value $\tau_{i}=0.5 \mathrm{~ms}$ was taken.

In case of lack of time dependence of the laser radiation intensity and time temperature distribution into the material is described by the following function [13]:

$$
T(z):=2 \cdot \frac{A}{\lambda} \cdot q \cdot \sqrt{a \cdot \tau_{i}} \cdot\left(\operatorname{ierfc} \frac{z}{2 \sqrt{a \cdot \tau_{i}}}\right)
$$

where $\mathrm{z}$ - the coordinate counted inward from the surface, $\mu \mathrm{m}, A-$ absorption coefficient of laser radiation $(A=0.35), q-$ the power density of laser radiation, $\mathrm{W} / \mathrm{m}^{2}$, ierf $c$ - the function of probability multiple integral [14].

The tabular value of the function probability multiple integral was used in calculations. The required energy is calculated according to the formation of a hardened area, $50 \mu \mathrm{m} \mathrm{min}$. The result was the choice of the following power values of the laser pulse of $1 \mathrm{~J}$ and $1.2 \mathrm{~J}$. Graphical results of the temperature modeling of the material at a point of time $\tau_{i}=0.5 \mathrm{~ms}$ that meets the requirements is shown in fig. 1 . The diameter of the focused laser radiation is $\mathrm{d}=1 \mathrm{~mm}$.

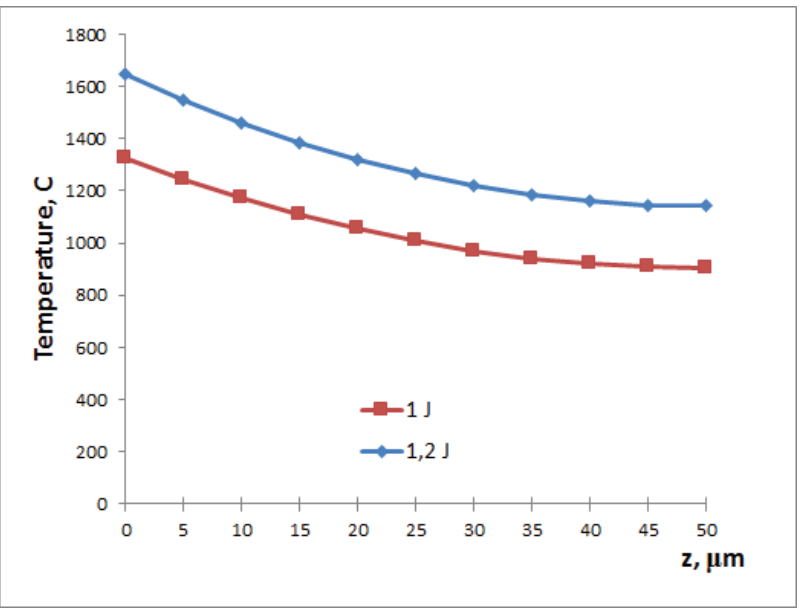

Fig. 1. Temperature distribution deep into at the point of time.

Laser heating is characterized by a high temperature gradient and considerable nonequilibrium transformations. It shifts the phase transformation to higher temperatures [11]. Therefore the estimated surface temperature is chosen within the range 1100$15000 \mathrm{C}$.

Metallographic studies are carried out with the microscope Neophot-21, the microhardness determination are made with the microthermometry PMT-3.

\section{Experimental results and discussion}

The microstructure formed in the surface layer shown in fig. 2.

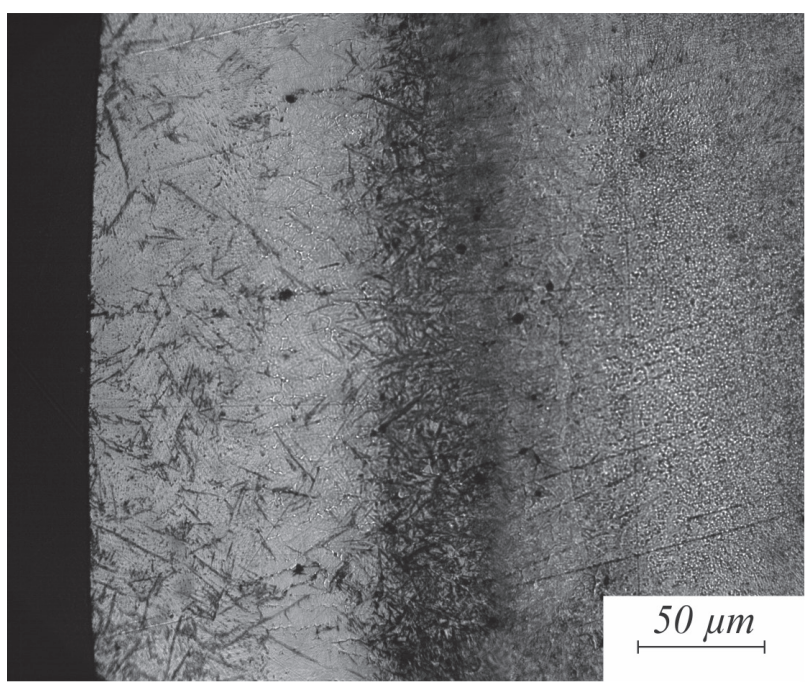

Fig. 2. Microstructure of the treated area.

Microhardness measurements were made deep into samples. Obtained values are shown in fig. 3.

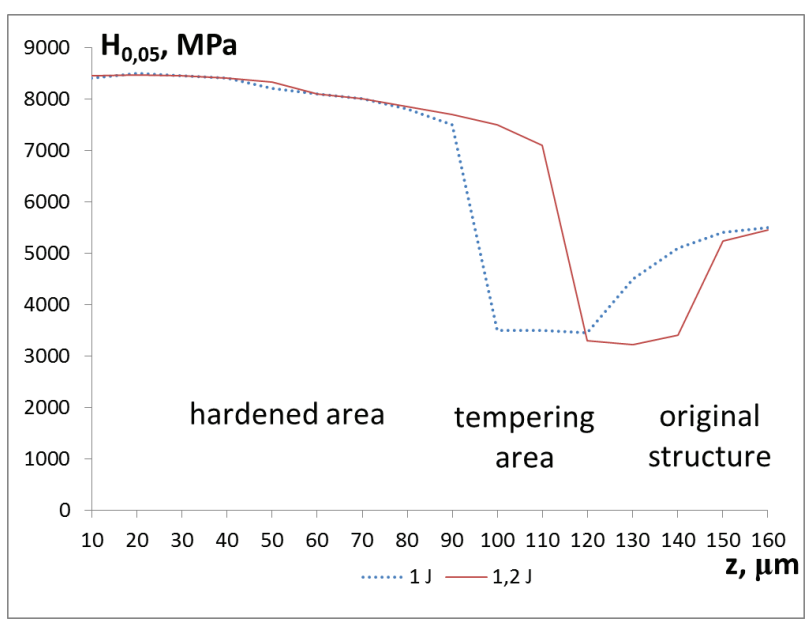

Fig. 3. Microhardness deep into the sample.

As a result of laser hardening two characteristic areas are formed: the area of hardening consisting of martensite, residual austenite and cementite and tempering area, which is a mixture of perlite of various dispersity.

The maximum value of the microhardness is to 8500 $\mathrm{MPa}$. The hardened area when energy pulse used is $1 \mathrm{~J}$, averaged $90 \mu \mathrm{m}$, the pulse energy $1.2 \mathrm{~J}-110 \mu \mathrm{m}$. 
The laser processing of band saws with pulse energy of $2 ; 2.5$; and $3 \mathrm{~J}$ was made to control the design theoretical model. The melt bath is formed after the use of such modes on the surface of the tool, as the result dendritic cast structure is formed (figs. 4, 5). It should be noted that the wider heat affected area was formed. The maximum value of the microhardness is $6900 \mathrm{MPa}$. In comparison with pulse energy of $1.2 \mathrm{~J}$ there was no the increase of the hardened area. This is due to the low thickness of the band saw preventing the high speed of cooling by increasing the impact energy. To ensure hardening in the autohardening mode heat is removed; it limits significantly the technological reproducibility of the process.

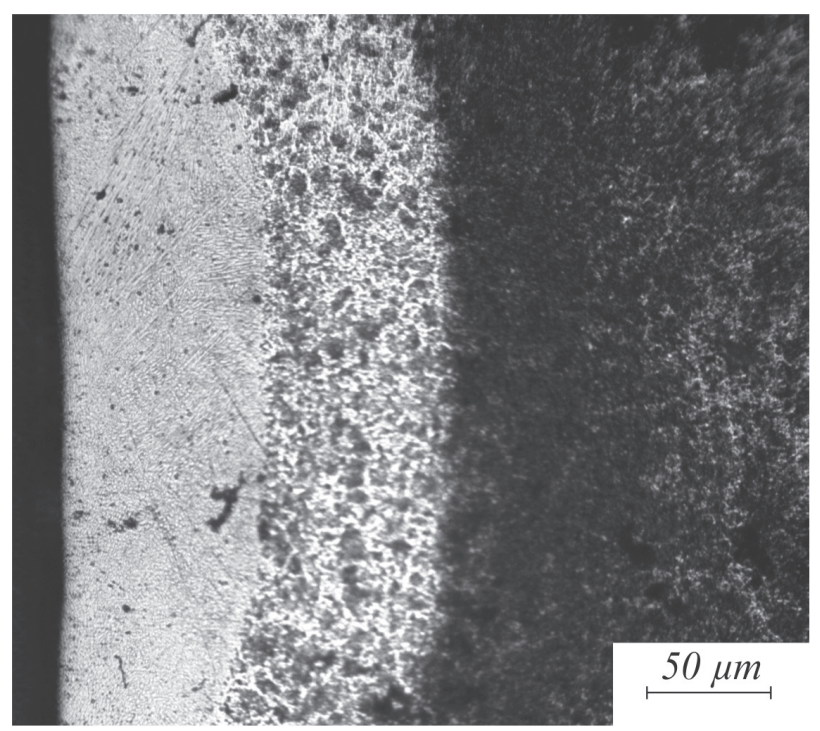

Fig. 4. Microstructure of the treated area.

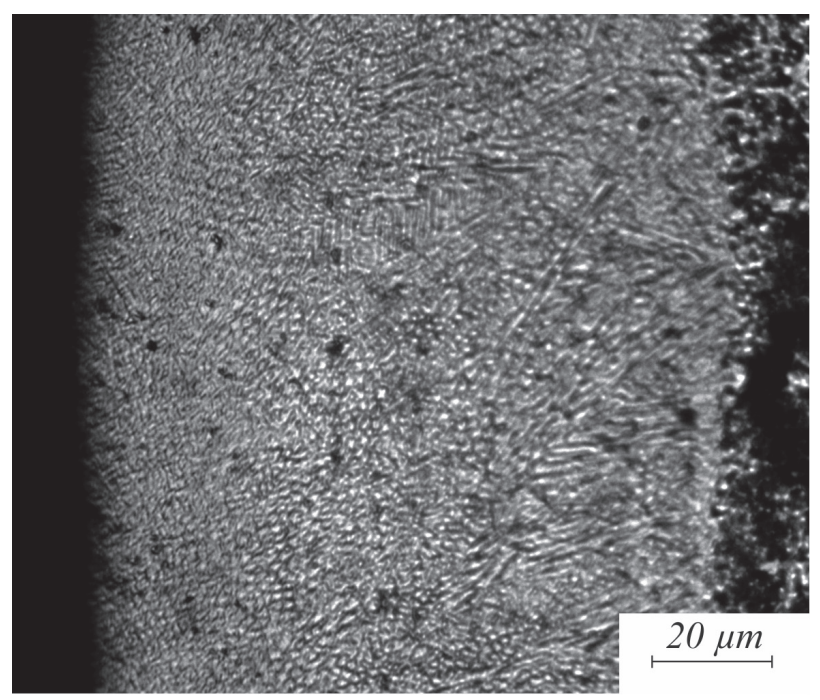

Fig. 5. Dendritic cast structure.

\section{Conclusions}

1. It is shown the fundamental capability of improving the strength performance of band saws made of tool steel $9 \mathrm{CrV}$ by means of pulsed laser radiation.
2. The modes of the pulsed laser radiation are selected analytically and confirmed experimentally. They increase the microhardness of the samples of $1 \mathrm{~mm}$ thick to $8500 \mathrm{MPa}$ without additional heat removal during processing.

3. Hardening by pulsed laser radiation is used to determine the band saws areas. There laser processing increases to the maximum the durability of the saw blade.

\section{References}

1. D. G. Sergeev, All-Russian annual scientific and technical conference "Society, science, innovation", p. 1163-1167 (2016)

2. D. G. Sergeev, M. N. Yurkin All-Russian annual scientific and technical conference "Society, science, innovation”, p. 1280-1283 (2012)

3. V. P. Ivanovskiy, D. Y. Kovaleva Complex criterion of quality tools. Actual tendences of scientific researches of the XXI century: theory and practice, 3, p. 385-388 (2015)

4. Y. I. Mulin, O. V. Kazannikov, V. D. Vlasenko Hardening of cutting tools of bandsaw machines with formation on their working surfaces of functional covers with electro spark processing. The Bulletin of the Pacific State University, p. 91-98 (2011)

5. A. F. Dulevich The works of BGTU. Series. II, Forest and woodworking industry, XVII, p. 331-333 (2009)

6. S. V. Kiselev, A. V. Blokhin, A. F. Dulevich Band saws with high durability. Actual problems of forest complex, 46, p. 153-155 (2016)

7. N. N. Rykalin, A. A. Uglov, N. V. Zuev and others Laser and electron ray processing of materials (1985)

8. A. A. Uglov, V. M. Makhtunov, T. P. Shmyreva, I. Y.Smurov, M. B. Ignatiev, Phisics and chemistry of materials treatment, 5 (1986)

9. A. N. Safonov, A. G. Grigoriants, Laser methods of heat treatment in machine building (1986)

10. E. A. Marinin, M. A. Surovcev All-Russian annual scientific and technical conference "Society, science, innovation", p. 1266-1267 (2014)

11. G. N. Gavrilov, Engineering and mastering of technologies of surface heat hardening and cladding of metallic materials by laser emission (2000)

12. A. S. Okhotin, R. P. Borovikova, T. V. Nechaeva, A. S. Pushkarevskiy, The heat conductivity of solid bodies (1984)

13. N. N. Rykalin, Laser and electron ray processing of materials (1985)

14. J. F. Asmus, S. F. Baker, Record of 10th Symposium on Electron, Ion and Laser Beam Technology (L. Marton, ed.), p. 241-246 (1969) 